\title{
Administration of interferon- $\gamma$ to pregnant rats reverses the depressed adjuvant-induced arthritis of their chronically Trypanosoma cruzi-infected offspring
}

G. Didoli, S. Revelli, H. Davila, M.E. Ferro,

M. Romero-Piffiguer and 0 . Bottasso
Instituto de Inmunología, Facultad de Ciencias M édicas,

Universidad Nacional de Rosario, Santa Fe, Rosario, Argentina

\section{Correspondence}

0 . Bottasso

Instituto de Inmunología

Facultad de Ciencias Médicas

Santa Fe 3100

Rosario (2000)

Argentina

Fax: + 54-341-4804-569

E-mail: postmaster@fmurb.sld.ar

Research supported in part by the Secretariat of Science and Technology, Universidad Nacional de Rosario.

Received June 10, 1998 Accepted March 3, 1999

\section{Abstract}

We demonstrated that administration of interferon gamma (IFN- $\gamma$ ) to the inbred "l" strain of pregnant rats conferred partial resistance on their offspring to challenge with Trypanosoma cruzi. We now examine if this intervention also modifies the reportedly immunodepressed cellular responses which occur during chronic infection. Offspring were born to mothers undergoing one of the following procedures during gestation: subcutaneous injections of recombinant rat IFN- $\gamma$, $50,000 \mathrm{IU} / \mathrm{rat}$, five times/week for 3 weeks, which was started on the day of mating (IFN-Mo); infection with $10^{6}$ trypomastigotes of $T$. cruzi at 7, 14, and 21 days after mating plus IFN- $\gamma$ treatment as given to the former group (TcIFN-Mo); the same protocol except that physiological saline was injected instead of IFN- $\gamma$ (Tc-Mo); injection of physiological saline only (control-Mo). All offspring groups $(\mathrm{N}=8$ 10 /group) were infected at weaning and were assessed 90 days later for their adjuvant-induced arthritic response or levels of major $\mathrm{T}$ cell subsets in spleen and lymph nodes. TcIFN-Mo and IFN-Mo offspring showed a reestablished arthritic response, which remained within the range seen in controls. Immunolabeling studies on parallel groups of 90-day-infected offspring showed that the inverse CD4/CD8 cell ratio that is usually seen in lymphoid organs from these chronically infected rats (median 0.61) appeared to have recovered in the TcIFN-Mo and IFN-Mo groups (median 1.66 and 1.78, respectively) and was not different from uninfected controls (1.96). These studies indicate that early stimulation with IFN- $\gamma$ is able to reverse the immunosuppressive state that is usually present during the chronic period of the experimental infection.
Key words

- Interferon gamma

- Adjuvant arthritis

- T. cruzi

- $T$ cell subsets 


\section{Introduction}

Inoculation of inbred "l" rats with a virulent strain of Trypanosoma cruzi, the etiologic agent of Chagas' disease, results in an experimental disease that mimics several aspects of chagasic infection in humans. In fact, challenge with living trypomastigotes at weaning is followed by a self-controlling acute infection characterized by easily noticeable parasitemias lasting up to 30 days postinfection ( $p i)$, together with the synthesis of specific antibodies that reach their maximum titers at 30 days $p i$, and persist within these levels thereafter. Well after the acute episode is resolved, 60 to $80 \%$ of these rats develop a mild chronic focal myocarditis consisting of mononuclear cell infiltration and destruction of myocardial muscle fibers (1-4).

Consistent with human and mouse studies documenting that chronic T. cruzi infection coexists with impaired immune responses to unrelated parasite antigens (5-7), chronically $T$. cruzi-infected "l" rats also exhibit down-regulated cellular immune responses when challenged with complete Freund adjuvant (CFA) for inducing adjuvant arthritis (AA) $(8,9)$. Accompanying these abnormalities, immunolabelling studies have shown that spleen and lymph nodes (LN) from chronically infected rats display an inverse $\mathrm{CD} 4 / \mathrm{CD} 8 \mathrm{~T}$ cell ratio in the presence of increased levels of mononuclear cells expressing class II major histocompatibility (MHC) antigens $(4,10)$.

Since stimulation of a pregnant host with various immunologic elements, i.e., cells, antigens or antibodies, is capable of influencing the immune response of the offspring (11-13), we have recently investigated the effect of $T$. cruzi infection and contact with interferon gamma (IFN- $\gamma$ ) during rat pregnancy on the course of the trypanosomal infection further elicited in offspring (14). Because our rats become highly resistant to T. cruzi when challenged in adult life (15),
IFN- $\gamma$ was also given to rat mothers in an attempt to reproduce what may happen when the host is effectively infected and synthesis of endogenous IFN- $\gamma$ is more likely to be increased. Our model proved to be useful in demonstrating that administration of IFN- $\gamma$ to pregnant rats largely protected their offspring against further challenge with $T$. cru$z i$, with young born to mothers that had also been infected during gestation displaying the lowest parasitemias (14). In view of this observation we now wished to ascertain whether administration of IFN- $\gamma$ to pregnant rats could also modify the reportedly immunodepressed responses of chronically infected offspring. Thus, in the present study we evaluated the arthritogenic response to challenge with CFA and determined the major T lymphocyte populations.

\section{Material and Methods}

\section{Rats and infection}

Male inbred "l" rats were used in the offspring experiments. Young were infected by the subcutaneous $(s c)$ route with $10^{6}$ trypomastigotes of the Tulahuén strain of $T$. cruzi. Infective blood trypomastigotes were maintained by weekly passage in CBi mice.

\section{Interferon gamma}

Recombinant rat IFN- $\gamma$ was a gift from Roussel Uclaf Laboratories (Romainville, France). Its biological activity was $1 \times 10^{7}$ $\mathrm{IU} / \mathrm{mg}$ protein, and the endotoxin content, less than $0.12 \mathrm{EU} / \mathrm{vial}$, was measured in a limulus amebocyte lysate assay. After reconstitution, the cytokine was administered by $s c$ injection at a daily dose of 50,000 IU. This schedule was based on a study in which 20,000 IU given to 21-day-old offspring proved to be biologically active and safe (4) and a weight-equivalent dose of 50,000 IU administered to pregnant rats had no effect on pregnancy outcome (14). 


\section{Experimental design}

Four groups of 70-day-old female rats were mated with syngeneic sires. The first group received a cycle of $s c$ injections of recombinant rat (Rr)IFN- $\gamma$ (Roussel Uclaf), $50,000 \mathrm{IU} /$ rat 5 times a week for 3 weeks, which was started on the day of mating. The second group was infected with an sc injection of $10^{6}$ living trypomastigotes at 7, 14, and 21 days after mating, plus treatment with RrIFN- $\gamma$ as administered to group 1. Pregnant rats were infected at weekly intervals in an attempt to produce a more evident infection, considering that infection of adult rats, pregnant or not, results in a scarcely noticeable acute disease $(3,15)$. A similar infection schedule was applied to group 3, which received physiological saline instead of RrIFN$\gamma$. Group 4 was only injected with physiological saline (group 1 schedule) and served as controls. The young were nursed by their mothers until weaning at 21 days. During this time no parasites were detected in the peripheral blood of rats born to infected mothers. Twenty-one-day-old offspring were then infected with $1 \times 10^{6} \mathrm{~T}$. cruzi and divided into four experimental groups: rats born to IFN- $\gamma$-treated mothers (IFN-Mo); rats born to infected and IFN- $\gamma$-treated mothers (TcIFN-Mo); rats born to infected mothers (Tc-Mo), and rats born to uninfected control mothers (control-Mo). A simultaneous group of uninfected offspring born to untreated mothers was also included for comparison (controls).

\section{Induction and assessment of adjuvant-induced arthritis}

Adjuvant arthritis in offspring was induced at 90 days $p i$ by injecting $0.1 \mathrm{ml}$ of CFA containing $5 \mathrm{mg} / \mathrm{ml}$ heat-killed Mycobacterium tuberculosis (H37Ra, Difco Laboratories, Detroit, MI), into the right hind foot pad. In this strain, AA develops mostly in the injected limb. Kinetic studies demonstrated that early arthritic signs are noticeable 7 days after induction, and AA is fully developed by the end of the second week postinduction. Microscopy studies have revealed that affected joints are heavily infiltrated by lymphocytes, macrophages, epithelioid and giant multinucleate cells resembling a chronic granulomatous reaction (16). The arthritis was evaluated at $7,15,20$ and 30 days postinduction by direct examination of individual joints using a semiquantitative scale (10). The arthritis scores were calculated as follows: smaller joints (metatarsophalangeal and interphalangeal), 1 point; larger joints (tarsus and ankle), 2 points. The individual score was doubled if swelling was more severe than ordinarily observed. All rats were evaluated by the same operator blinded to the study groups.

\section{Preparation of spleen and lymph node cells}

Spleens from parallel groups of 90-dayinfected offspring and age-matched controls were removed and collected on a sterile disposable 60-mm Petri dish containing 5$10 \mathrm{ml}$ of Hank's balanced salt solution (HBSS), pH 7.2. The spleens were prepared by gently teasing in HBSS, the debris were separated and the single cell suspension was collected. Spleen mononuclear cells were separated by Ficoll-Hypaque gradient centrifugation. The cells at the medium-FicollHypaque interface were collected, washed twice with HBSS and resuspended in RPMI 1640 medium. Lymph node cells were prepared as total spleen cells, washed twice and resuspended in RPMI 1640. Spleen and LN cells were assessed for viability by the Trypan blue exclusion test.

\section{Evaluation of cell surface markers}

An indirect immunofluorescence test using monoclonal antibodies (Bioproducts for Science, Madison, WI, USA) directed against W3/25 (rat $T$ helper/inducer CD4 subset) 
and OX-8 (rat $\mathrm{T}$ cell cytotoxic/suppressor CD8 subset) surface markers was performed according to the procedure described by Hickey et al. (17). Briefly, spleen and LN cells were suspended in RPMI 1640 at a final concentration of $1 \times 10^{6}$ cells $/ \mathrm{ml}$. Three hundred microliters of the cell suspension was centrifuged and the cell pellet obtained was mixed with $100 \mu \mathrm{l}$ of an appropriate dilution for monoclonal antibodies and incubated at $4^{\circ} \mathrm{C}$ for $60 \mathrm{~min}$. The cells were collected by centrifugation and washed twice with HBSS containing $0.02 \%$ sodium azide. After the second wash the cell pellets were resuspended in $15 \mu \mathrm{l}$ of FITC-conjugated rabbit anti-mouse IgG diluted 1:4 and then incubated for $60 \mathrm{~min}$ at $4^{\circ} \mathrm{C}$. The samples were again washed twice in HBSS containing sodium azide. A minimum of 200 cells were counted by ultraviolet microscopy to determine the percent of positive cells.

\section{Statistical analysis}

The statistical significance of the difference among groups was assessed by the Kruskall-Wallis analysis of variance and the Mann-Whitney U-test. A P value $<0.05$ was considered significant.

\section{Results}

Age-matched controls and 90-day T. cru$z i$-infected offspring were injected with CFA and later assessed for the severity of developed arthritis. Data from day 15 postinduction showed that control-Mo and Tc-Mo rats had a significantly lower arthritic score when compared to controls $(\mathrm{P}<0.001$; Figure 1). This represented a $40-45 \%$ reduction in arthritis severity, and was consistent with published data (8-10). As shown in the same Figure, offspring born to mothers receiving IFN- $\gamma$ during gestation (TcIFN-Mo and IFNMo groups) presented a reestablished arthritic response which remained within the range observed in controls. A similar pattern of differences amongst groups was found when analyzing results from the later time evaluations (data not shown).

We have previously demonstrated that spleen and LN from chronically infected rats contain an inverse CD4/CD8 cell ratio. To determine whether the recovered AA coincided with regional modifications in major $\mathrm{T}$ cell subsets by the time AA was induced, spleens and LN from parallel groups of 90day-infected rats and age-matched controls were assessed for $\mathrm{CD}^{+}$and $\mathrm{CD}^{+}$levels. Data are reported as percent values, since the groups showed no significant differences in absolute numbers of spleen and LN mononuclear cells. Confirming and extending earlier observations $(4,10)$, spleens and $\mathrm{LN}$ from chronically infected rats (control-Mo group) displayed decreased levels of $\mathrm{CD}^{+}$and increased levels of $\mathrm{CD}^{+}$cells (Figure 2, panels $\mathrm{A}$ and $\mathrm{B}$ ). Reduced numbers of $\mathrm{CD}^{+}$ cells were also observed in Tc-Mo, but not in TcIFN-Mo or IFN-Mo rats, whose $\mathrm{CD} 4^{+}$cell values not only appeared to be recovered but were significantly higher than control values (Figure 2A). With regard to $\mathrm{CD}^{+}$cells, it was clear that $\mathrm{LN}$ from the four groups of $T$. cruzi-infected rats contained higher levels of this $\mathrm{T}$ cell subset in relation to controls

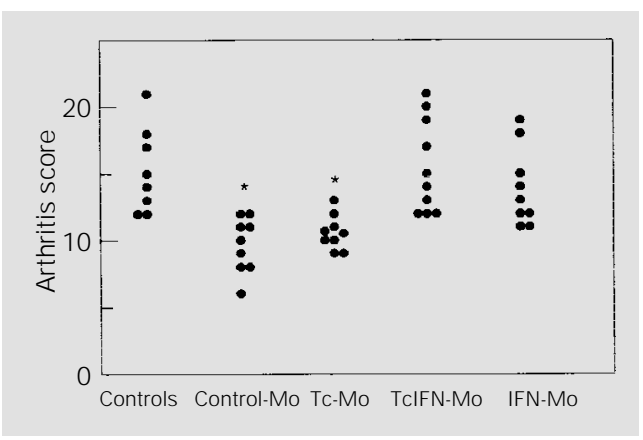

Figure 1 - Adjuvant-induced arthritis (AA) in chronically T. cruzi-infected rats. Each point represents an individual result. Control-Mo, Rats born to control mothers; Tc-Mo, rats born to infected mothers; TcIFN-Mo, rats born to infected and IFN- $\gamma$-treated mothers; IFN-Mo, rats born to IFN- $\gamma$-treated mothers. AA was elicited on day 90 of infection, and assessed at 15 days postinduction. ${ }^{*} \mathrm{P}<0.001$ for control-Mo and TC-Mo compared to controls (Kruskall-Wallis analysis of variance). 
$(\mathrm{P}<0.01)$. Spleen $\mathrm{CD}^{+}$cells in the infected groups were also above those from controls, but differences between this group and IFNMo remained nonsignificant (Figure 2B). Further comparisons revealed that this increase in $\mathrm{CD}^{+}$cell populating in the spleens and LN of infected groups was less pronounced in TcIFN-Mo and IFN-Mo, and significantly different from Tc-Mo rats ( $\mathrm{P}<0.05$ and $\mathrm{P}<0.025$, respectively) or control-Mo (IFN-Mo only, $\mathrm{P}<0.025$ ). The relationship between major $\mathrm{T}$ cell subsets is further illustrated in Table 1. It can be seen that control-Mo and Tc-Mo had an inverse CD4/CD8 cell ratio, which appeared to be partially and fully reversed in TcIFN-Mo and IFN-Mo, respectively.

\section{Discussion}

In addition to protecting offspring from acute $T$. cruzi infection (14), the present observations indicate that administration of IFN- $\gamma$ to pregnant rats also reversed the immunodepressed responses occurring during the chronic period of this experimental infection (8-10). In fact, offspring born to mothers receiving IFN- $\gamma$ during gestation (TcIFN-

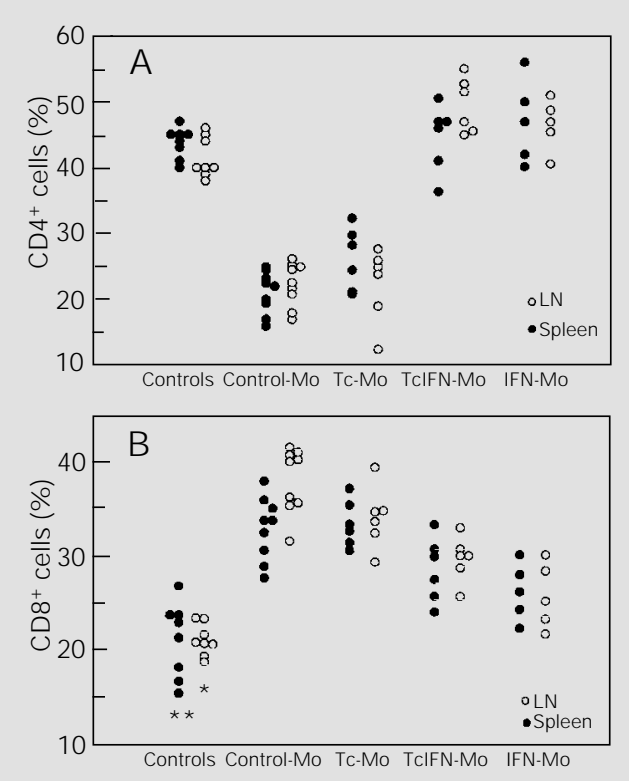

Mo and IFN-Mo groups) not only presented a recovered arthritic response but also displayed substantial modifications in the levels of major $\mathrm{T}$ lymphocyte populations. Changes in immunocompetent cells populating lymphoid organs may be fundamental in determining the recovery from adjuvantinduced arthritis for several reasons. It has been proposed that $\mathrm{LN} \mathrm{T}$ cells, in particular the helper/inducer CD4 subset, play an essential role in both the initiation and perpetuation of joint inflammatory lesions (1820). Furthermore, there is evidence that some form of suppressor activity can be demonstrated within the CD8 T cell subset (21). On the basis of these considerations, suboptimal arthritogenic responses in control-Mo and Tc-Mo groups may be interpreted to be associated with the imbalance between $\mathrm{CD}^{+}$ and $\mathrm{CD}^{+}$cells. Consistent with this reasoning are data from offspring born to IFN- $\gamma$ mothers in which restored AA coincided with a reestablished balance of major $T$ cell subsets. Additional support for the view that $\mathrm{T}$ cells populating the regional $\mathrm{LN}$ are critical for the establishment of arthritic lesions comes from our immunolabelling cell studies in LN from chronically $T$. cruzi-infected

Figure 2 - T cell subsets in spleens and popliteal lymph nodes from chronically $T$. cruzi-infected rats. Each point represents an individual result; filled circles indicate spleen and open circles data for lymph nodes (LN). Control-Mo, Rats born to control mothers; TC-Mo, rats born to infected mothers; TcIFN-Mo, rats born to infected and IFN- $\gamma$-treated mothers; IFN-Mo, rats born to IFN- $\gamma$-treated mothers. Assessment at 90 days pi. Panel A: Percent of $\mathrm{CD}^{+}$cells. $\mathrm{P}<0.001$ for control-Mo and Tc-Mo compared to other groups in both lymph nodes and spleen (Kruskall-Wallis analysis of variance). $\mathrm{P}<0.05$ for lymph node $\mathrm{CD}_{4}{ }^{+}$cells from TcIFN-Mo and IFN-Mo compared to controls (Mann-Whitney U-test). Panel B: Percent of $\mathrm{CD}^{+}$cells. $* \mathrm{P}<0.01$ for lymph node CD8 ${ }^{+}$ cells from controls compared to other groups (KruskallWallis analysis of variance). ${ }^{*} \mathrm{P}<0.01$ for spleen $\mathrm{CD}^{+}$ cells from controls compared to control-Mo, Tc-Mo, and TCIFN-Mo groups (Kruskall-Wallis analysis of variance). $\mathrm{P}<0.025$ for IFN-Mo compared to control-Mo and TC-Mo groups in both lymph nodes and spleen (Mann-Whitney U-test). P $<0.05$ for TcIFN-Mo compared to Tc-Mo rats in both lymph nodes and spleen (MannWhitney U-test). 
Table $1-\mathrm{CD}^{+}$and $\mathrm{CD} 8^{+}$cell ratios in the experimental groups.

Data are reported as median (range) of 5 to 9 rats per group. Control-Mo, Rats born to control mothers; Tc-Mo, rats bom to infected mothers; TcIFNMo, rats born to infected and IFN- $\gamma$-treated mothers; IFN-Mo, rats born to IFN- $\gamma$-treated mothers. *P $<0.001$ compared to controls (Mann-Whitney Utest). ${ }^{* *}$ Statistically higher than control-Mo and TCMo and lower than controls, $\mathrm{P}<0.02$ (MannWhitney U-test).

\begin{tabular}{lll}
\hline \multirow{2}{*}{ roups } & \multicolumn{2}{c}{ CD4/CD8 cell ratio } \\
\cline { 2 - 3 } & \multicolumn{1}{c}{ Spleen } & \multicolumn{1}{c}{ Lymph nodes } \\
\hline Controls & $2.04(2.88-1.7)$ & $1.96(2.23-1.83)$ \\
Control-Mo & $0.68(0.9-0.45)^{*}$ & $0.61(0.69-0.48)^{*}$ \\
TC-Mo & $0.74(0.97-0.64)^{*}$ & $0.73(0.85-0.32)^{*}$ \\
TCIFN-Mo & $1.53(1.82-1.4)^{* *}$ & $1.66(2.05-1.83)^{* *}$ \\
IFN-Mo & $1.77(2.5-1.39)$ & $1.78(2.09-1.6)$
\end{tabular}

rats subjected to cyclophosphamide (Cy) treatment before arthritis induction (10). Cyinduced recovery of AA was accompanied by a restored relationship between $\mathrm{CD} 4^{+}$and $\mathrm{CD}^{+}$cells. Similarly, studies at the time of fully established arthritic lesions revealed a significant increase of $\mathrm{CD}^{+}$along with reduced numbers of $\mathrm{CD}^{+}$, with the latter cell type being even further decreased in rats given $\mathrm{Cy}$.

The mechanism by which maternally given IFN- $\gamma$ was able to exert such long-term effects on the profile of immunocompetent cells populating lymphoid organs is unknown. Our findings may be due to changes in the expression of membrane cell markers or to a true modification of the number of cells present in the compartments, in direct relation to IFN- $\gamma$ administration or to the benign course of the experimental infection in offspring. Because of the inhibitory effect that $T$. cruzi was found to exert on the expression of CD3, CD4, and CD8 molecules by mitogen-activated lymphocytes (22), reduced parasite load resulting from attenuated infection would render such effects less evident or restricted to a particular cell marker. Alternatively, the reestablished
CD4:CD8 cell ratio may be due to a different lymphocyte redistribution in vivo, which usually does not occur during unprotected infection. From another standpoint, recent in vitro studies employing spleen $T$ cells from $T$. cruzi-infected BALB/c mice demonstrated an activation-induced programmed cell death by apoptosis affecting $\mathrm{CD} 4^{+}$cells but not $\mathrm{CD}^{+}$cells (23). Such a selective loss of $\mathrm{CD}^{+}$cells led the authors to assume it as being responsible for the inverse CD4:CD8 ratio seen during $T$. cruzi infection. Whether this also extends to our rat model and is less likely to occur in offspring delivered by IFN$\gamma$-treated mothers remains to be elucidated. IFN- $\gamma$ is known to play a role in apoptosis, but the full significance of its effects is still unclear (24).

IFN- $\gamma$ is known to play distinct roles in the development of various autoimmune processes (25-27). As regards human T. cruzi infection, in vitro synthesis of IFN- $\gamma$ by antigen-stimulated peripheral blood mononuclear cells was found to be significantly higher in patients with chronic cardiac involvement (28). This demonstration was taken to imply a detrimental role of this cytokine in the establishment of myocardial lesions, a complication which is thought to have an autoimmune component in its genesis (29). Nevertheless, in our model, treatment of acutely $T$. cruzi-infected rats with IFN- $\gamma$ caused no changes in the prevalence or the histological features of chronic myocardial lesions that further developed in these animals (4) even when IFN- $\gamma$ was administered during the chronic phase (Revelli S, Musso O, Valenti J, Falcoff E and Bottasso OA, unpublished data). These divergent results may be explained by host differences and/or the distinct methodological approaches employed to establish a relationship between presence of IFN- $\gamma$ and heart involvement. Further studies are required to clarify this issue.

Beyond these considerations, the present studies provide the first demonstration that 
early stimulation with IFN- $\gamma$ caused substantial modifications in the course of the trypanosomal infection in offspring, which reflected not only an ameliorated acute disease but also a reversal of the immunosuppressive state accompanying chronic infection. If our findings can be extended to other mammalian species, the phenomenon may have important prognostic implications for naturally exposed populations. If a pregnant host experiences an increased IFN- $\gamma$ synthesis because of a concomitant T. cruzi infection, its offspring which do not develop congenital disease may present a better response to their own trypanosomiasis in the event they later become infected.

\section{References}

1. Revelli SS, Amerio N, Moreno HS, Valenti J L, Balbarrey H \& Morini J (1980). Enfermedad de Chagas cronica en la rata. Caracteristicas serologicas, electrocardiograficas e histopatologicas. Medicina, 40: 69-76.

2. Bottasso OA, Revelli SS, Dávila H, Valenti $\mathrm{J} L$, Musso OC, Ferro ME, RomeroPiffiguer M \& M orini J C (1993). Enhanced myocardial lesions in chronically Trypanosoma cruzi-infected rats subjected to adult thymectomy. Immunology Letters, 37: 175-180.

3. Davila HO, Revelli SS, Moreno HS, Valenti JS, Musso OC, Poli HO, Morini JC \& Bottasso OA (1994). Infection with Trypanosoma cruzi during pregnancy in rats and the decrease in chronic myocardial lesions in their infected offspring. American J ournal of Tropical Medicine and Hygiene, 50: 506-511.

4. Revelli S, Davila H, Ferro ME, RomeroPiffiguer M, Musso O, Valenti J Bernabo J , Falcoff E, Wietzerbin J \& Bottasso OA (1995). Acute and chronic experimental Trypanosoma cruzi infection in the rat. Response to systemic treatment with recombinant rat interferon gamma. Microbiology and Immunology, 39: 275-282.

5. Reed SG, Roters S \& Goidl E (1983). Spleen cell-mediated suppression of IgG production to a non-parasite antigen during chronic Trypanosoma cruzi infection in mice. J ournal of Immunology, 131: 1978-1982.

6. Voltarelli J C, Donadi EA, Carvalho IF \& Falcão RP (1990). Lymphocyte subpopulations and neutrophil function in chronic human Chagas' disease. Revista do Instituto de Medicina Tropical de São Paulo, 32: 240-248.

7. Bottasso OA, Ingledew N, Keni M, Morini J , Pividori J F, Rook GAW \& Stanford J L (1994). The cellular immune response to common mycobacterial antigens is suppressed in persons seropositive for Trypanosoma cruzi. Lancet, 344: 1540-1541.
8. Revelli SS, Bottasso OA, Moreno HS, Dávila H, Amerio N \& Morini J C (1990). Depressed adjuvant arthritis in rats transferred with spleen cells from Trypanosoma cruzi infected syngeneic donors. Brazilian J ournal of Medical and Biological Research, 23: 567-571.

9. Revelli $\mathrm{S}$, Dávila $\mathrm{H}$, Moreno $\mathrm{H} \&$ Bottasso OA (1992). Depressed adjuvant arthritis in chronically Trypanosoma cruzi-infected rats. Reversal by cyclophosphamide. J ournal of Rheumatology, 19: 513-515.

10. Didoli G, Revelli S, Davila H, Ferro ME, Romero-Piffiguer M \& Bottasso O (1996). Cyclophosphamide-induced recovery of adjuvant arthritis in Trypanosoma cruziinfected rats is associated with substantial changes in T lymphocytes and class $\mathrm{II}^{+}$cells from draining lymph nodes. International J ournal of Immunopharmacology, 18: 127-133.

11. Kearney J F \& Vakil M (1986). Idiotypedirected interactions during ontogeny play a major role in the establishment of the adult B cell repertoire. Immunological Reviews, 94: 39-50.

12. Lemke H, Lange $\mathrm{H} \&$ Berek C (1994). Maternal immunization modulates the primary immune response to 2-phenyloxazolone in Balb/c mice. European J ournal of Immunology, 24: 3025-3030.

13. Martinez-AC, Toribio ML, De la Hera A, Cazenave PA \& Coutinho A (1986). Maternal transmission of idiotypic network interactions selecting available $T$ cell repertoires. European J ournal of Immunology, 16: 1445-1447.

14. Davila H, Revelli S, Didoli G, Bernabo J, Wietzerbin J, Falcoff E \& Bottasso OA (1996). Protection of young rats from acute Trypanosoma cruzi infection by interferon-gamma given to their mothers during pregnancy. American J ournal of Tropical Medicine and Hygiene, 54: 660664.

15. Revelli S, Moreno H, Berra H, Valenti J L, Nocito AL, Amerio N \& Morini J C (1987).
Influencia de la edad de la rata en la evolucion de la infeccion con Trypanosoma cruzi. Medicina, 47: 360-366.

16. Revelli $\mathrm{S}$, Bottasso $\mathrm{OA}$, Moreno $\mathrm{H}$, Valenti J L, Nocito A, Amerio N \& Morini JC (1986). La enfermedad del adyuvante en ratas infectadas experimentalmente con Trypanosoma cruzi. Revista do Instituto de Medicina Tropical de São Paulo, 28: 154-159.

17. Hickey WF, Gonatas NK, Kimura H \& Wilson DR (1983). Identification and quantitation of $\mathrm{T}$ lymphocyte subset found in the spinal cord of the Lewis rat during acute experimental allergic encephalomyelitis. J ournal of Immunology, 131: 28052809.

18. Holoshitz J , Matitiau A \& Cohen IR (1984). Arthritis induced in rats by cloned T lymphocytes responsive to mycobacteria but not to collagen type II. J ournal of Clinical Investigation, 73: 211-215.

19. Taurog J D, Sandberg GP \& M ahowald ML (1983). The cellular basis of adjuvant arthritis. II. Characterization of the cells mediating passive transfer. Cellular Immunology, 80: 198-204.

20. Billingham MEJ, Hicks $C \&$ Carney $S$ (1990). Monoclonal antibodies and arthritis. Agents and Actions, 29: 77-87.

21. Le Gros G \& Erard F (1994). Non-cytotoxic, IL-4, IL-5, IL-10 producing CD8 ${ }^{+} \mathrm{T}$ cells: their activation and effector functions. Current Opinion in Immunology, 6: 453-457.

22. Sztein MB, Cuna WR \& Kierszenbaum $F$ (1990). Trypanosoma cruzi inhibits the expression of CD3, CD4, CD8, and IL-2r by mitogen-activated helper and cytotoxic human lymphocytes. J ournal of Immunology, 144: 3558-3562.

23. Lopes MF, da Veiga VF, Santos AR, Fonseca MEF \& DosReis GA (1995). Activation-induced $\mathrm{CD} 4+\mathrm{T}$ cell death by apoptosis in experimental Chagas' disease. J ournal of Immunology, 154: 744-752.

24. Boehm U, Klamp T, Groot M \& Howard 
JC (1997). Cellular responses to interferon- $\gamma$. Annual Review of Immunology, 15: 749-795.

25. Billiau A, Heremans $\mathrm{H} \&$ Vandekerckhove F (1988). Enhancement of experimental allergic encephalomyelitis in mice by antibodies against IFN-gamma. J ournal of Immunology, 140: 1506-1510.

26. J acob CO, Van der Meide PH \& McDevitt HO (1987). In vivo treatment of (NZB X
NZW)F1 lupus-like nephritis with monoclonal antibody to $\gamma$ interferon. J ournal of Experimental Medicine, 166: 798-803.

27. Kroemer G \& Martinez AC (1991). Cytokines and autoimmune diseases. Clinical Immunology and Immunopathology, 61: 275-295.

28. Bahia-Oliveira LMG, Gomes J AS, Rocha MOC, Moreira MCV, Lemos EM, Luz ZMP, Pereira MES, Coffman RL, Dias J CP,
Cançado J R, Gazzinelli G \& Corrêa-Oliveira $\mathrm{R}$ (1998). IFN- $\gamma$ in human Chagas' disease: protection or pathology? Brazilian J ournal of Medical and Biological Research, 31: 127-131.

29. Rossi MA \& Ramos SG (1996). Pathogenesis of chronic Chagas' myocarditis: an overview. Cardiovascular Pathology, 5: 197-202. 